\title{
Repercussões imunes em pacientes com dispepsia funcional: Uma revisão sistemática
}

\author{
Immune repercussions in patients with functional dyspepsia: A systematic review \\ Repercusiones inmunitarias en pacientes con dispepsia funcional: Una revisión sistemática
}

Recebido: 01/07/2021 | Revisado: 09/07/2021 | Aceito: 13/07/2021 | Publicado: 23/07/2021

\author{
Natálhya Furtado Oliveira Nobre \\ ORCID: https://orcid.org/0000-0001-5127-7059 \\ Centro Universitário de Patos, Brasil \\ E-mail: natalhyafurtado@gmail.com \\ Matusalém Marcelino Cândido \\ ORCID: https://orcid.org/0000-0002-8270-8162 \\ Centro Universitário de Patos, Brasil \\ E-mail: matu-salem1@ @otmail.com \\ Larissa Mercielly Nóbrega Medeiros \\ ORCID: https://orcid.org/0000-0002-1541-3911 \\ Centro Universitário de Patos, Brasil \\ E-mail: larissamedeiros@med.fiponline.edu.br \\ Milena Nunes Alves Sousa \\ ORCID: https://orcid.org/0000-0001-8327-9147 \\ Centro Universitário de Patos, Brasil \\ E-mail: milenanunes@fiponline.edu.br
}

\begin{abstract}
Resumo
Introdução: A Dispepsia Funcional (DF) é um distúrbio crônico ou intermitente do estômago pela perda do equilíbrio homeostático, fazendo parte das Doenças Gastrointestinais Funcionais (FGIDs). Vários fatores podem estar envolvidos com a doença e suas repercussões imunes. Objetivo: Avaliar, em pacientes com Dispepsia Funcional, qual o risco de repercussões imunes. Método: Revisão Sistemática da Literatura. A busca de dados ocorreu em duas bases: Biblioteca Virtual em Saúde (BVS) e PubMed. A pergunta norteadora segue o acrônimo PO, sendo P os pacientes com DF e O as repercussões imunes. Utilizou-se a combinação dos descritores: "Dyspepsia" AND "Immune System". Os critérios de inclusão utilizados foram qualquer ano de publicação, em português e inglês, artigos completos online e estudos de Coorte e Transversais que abordem a questão PO. Após a identificação inicial dos artigos, foi realizada leitura aos pares e seleção conforme critérios de elegibilidade. Resultados: Foram selecionados cinco artigos, com estudos do tipo Coorte e Transversais. Em pacientes com DF, há maior probabilidade de desenvolver determinadas doenças pela desregulação imunológica causada, como atopias, infecções e transtornos de humor. Um dos principais fatores causais é a inflamação acarretada por infecções, em que o estresse leva ao aumento das citocinas inflamatórias pelo organismo, que pode levar a quadros alérgicos e disfunções neurológicas. Conclusão: Evidenciou-se uma correlação entre a DF e o surgimento de atopias e transtornos de humor posteriores. Contudo, faz-se necessário investir em mais artigos para elucidar melhor a sobreposição entre tais doenças.
\end{abstract}

Palavras-chave: Dispepsia; Sistema imune; Transtornos do humor; Gastroenteropatias.

\begin{abstract}
Introduction: Functional Dyspepsia (FD) is a chronic or intermittent stomach disorder due to loss of homeostatic balance, being part of Functional Gastrointestinal Diseases (FGIDs). Several factors can be involved with the disease and its immune repercussions. Objective: To evaluate, in patients with Functional Dyspepsia, the risk of immunological repercussions. Method: Systematic Literature Review. The data search strategy used was obtained through two databases: Biblioteca Virtual em Saúde (BVS) and PubMed. The guiding question follows the acronym $\mathrm{PO}$, with $\mathrm{P}$ being patients with $\mathrm{FD}$ and $\mathrm{O}$ as immune repercussions. A combination of descriptors was used: "Dyspepsia" AND "Immune System". The inclusion criteria used were any year of publication, in Portuguese and English, full online articles and Cohort and Cross-sectional studies that address the PO issue. After the initial identification of the articles, they were read in pairs and selected according to eligibility criteria. Results: Five articles were selected, with Cohort and Cross-sectional studies. In patients with FD, there is a greater probability of developing certain diseases caused by immune dysregulation, such as atopy and mood disorders. One of the main causal factors is inflammation caused by infections, in which stress has led to an increase in inflammatory cytokines throughout the body, which can lead to allergic conditions and neurological disorders. Conclusion: There was evidence of a correlation between FD and the onset of atopy and later mood disorders. However, it is necessary to invest in more articles to better elucidate the overlap between such diseases.
\end{abstract}

Keywords: Dyspepsia; Immune system; Mood disorders; Gastrointestinal diseases. 


\begin{abstract}
Resumen
Introducción: La dispepsia funcional (DF) es un trastorno estomacal crónico o intermitente debido a la pérdida del equilibrio homeostático, que forma parte de las Enfermedades Gastrointestinales Funcionales (TFGI). Varios factores pueden estar involucrados con la enfermedad y sus repercusiones inmunológicas. Objetivo: evaluar, en pacientes con dispepsia funcional, el riesgo de repercusión inmunitaria. Método: Revisión sistemática de la literatura. Los datos se buscaron en dos bases de datos: Biblioteca Virtual em Saúde (BVS) y PubMed. La pregunta orientadora sigue el acrónimo PO, siendo $\mathrm{P}$ los pacientes con DF y $\mathrm{O}$ las repercusiones inmunes. Se utilizó la combinación de descriptores: "Dyspepsia" AND "Immune System". Los criterios de inclusión utilizados fueron cualquier año de publicación, en portugués e inglés, artículos completos en línea y estudios de cohortes y transversales que abordan el tema de las OP. Tras la identificación inicial de los artículos, se leyeron por parejas y se seleccionaron según criterios de elegibilidad. Resultados: Se seleccionaron cinco artículos, con estudios de cohortes y transversales. En los pacientes con EF existe una mayor probabilidad de desarrollar determinadas enfermedades provocadas por una desregulación inmunitaria, como atopia, infecciones y trastornos del estado de ánimo. Uno de los principales factores causales es la inflamación causada por infecciones, en la que el estrés conduce a un aumento de citocinas inflamatorias en todo el cuerpo, lo que puede provocar afecciones alérgicas y trastornos neurológicos. Conclusión: hubo evidencia de una correlación entre DF y la aparición de atopia y trastornos posteriores del estado de ánimo. Sin embargo, es necesario invertir en más artículos para dilucidar mejor la superposición entre estas enfermedades.

Palabras clave: Dispepsia; Sistema inmunológico; Trastornos del estado de ánimo; Enfermedades gastrointestinales.
\end{abstract}

\title{
1. Introdução
}

A Dispepsia Funcional (DF) é um distúrbio crônico ou intermitente da motilidade do estômago que faz parte do grupo de Doenças Gastrointestinais Funcionais (FGIDs), caracterizado pela perda do equilíbrio homeostático no intestino. Tal distúrbio é definido através dos Critérios Diagnósticos de Roma IV de 2016 que incluem: plenitude pós-prandial, saciedade precoce, dor epigástrica e queimação epigástrica, desde que o paciente não possua nenhuma causa orgânica ou metabólica para tais sintomas. Também pode haver outras manifestações, presentes em outras síndromes disfuncionais gastrointestinais, como azia, regurgitação, dor e distensão abdominal (Fan \& Talley, 2017; Burns et al., 2019) Por isso, é importantíssimo a realização de um diagnóstico diferencial qualificado.

De acordo com Fan e Talley (2017) a prevalência da doença é maior em mulheres, fumantes, pacientes positivos para Helicobacter pylori e usuários de anti-inflamatórios não esteroidais (AINEs). Os autores ainda ressaltam a relação entre doenças atópicas (asma, eczema, rinite alérgica e conjuntivite) e doenças reumatológicas autoimunes com a Dispepsia Funcional.

A etiopatogenia da DF é multifatorial. Como foi ressaltado por Burns et al. (2019), as FGIDs são explicadas através de um modelo biopsicossocial, pois envolvem fatores biológicos/fisiológicos, psicológicos e sociais. Em consonância, Fan e Talley (2017) explanam sobre alguns dos fatores envolvidos. São eles: estresse psicológico (destaque para a ansiedade e para a relação bidirecional entre o sistema nervoso central e o intestino que, quando desregulada, gera uma motilidade desordenada), genético (polimorfismos de nucleotídeo único/SNPs na subunidade 825 da proteína G beta3/GNB3), infecções (gastroenterite aguda prévia limitada ao intestino proximal, geralmente causada pela H. pylori, causando a DF pós-infecciosa), disfunção gastroduodenal (há sintomas como esvaziamento gástrico retardado, acomodação gástrica prejudicada e hipersensibilidade gástrica), dieta (destaque para alimentos ricos em gordura, fritos e picantes, os quais aumentam os níveis de colecistocinina plásmática/CCK) e inflamação duodenal (observou-se aumento no número de eosinófilos e mastócitos duodenais).

No que diz respeito às repercussões imunes, os dois fatores de maior relevância são o genético e a inflamação duodenal. O primeiro porque o polimorfismo de nucleotídeo único (SNP) atua em genes da função neuronal, da integridade da barreira mucosa e da regulação imunológica (Wouters \& Boeckxtaens, 2016). Porém, Burns et al. (2019) ressaltam que é improvável que o risco genético sozinho conduza a fisiopatologia das FIGDs. O segundo fator porque causa aumento do homing intestinal (linfócitos CD4+ $\alpha 4 \beta 7+\mathrm{CCR} 9+$ ) e dos níveis de citocinas na circulação periférica (Fan \& Talley, 2017).

Todos os fatores supracitados geram uma perturbação no epitélio intestinal e também apresentação de antígenos, culminando na ativação de células TCD4 (resposta imune do tipo Th2). Elas liberam Eotaxina que atua recrutando eosinófilos 
e ao degranularem eles causam todas as repercussões do processo inflamatório. Dentre elas pode-se citar: danos às fibras nervosas submucosas, desconforto, dor, perda de permeabilidade, diminuição da expressão de proteínas da junção apertada, aumento da ativação imunológica, liberação de células $\mathrm{T}$ homeing do intestino delgado, hipersensibilidade intestinal e liberação de citocinas. Destacam-se as citocinas por induzirem disfunção gastroduodenal e também extraintestinal como, por exemplo, a ansiedade (Wouters \& Boeckxtaens, 2016; Fan \& Talley, 2017).

O diagnóstico da Dispepsia Funcional é baseado na aplicação dos Critérios de Roma IV, já citados, associados ao diagnóstico diferencial, ao exame físico e aos testes laboratoriais (Wouters \& Boeckxtaens, 2016). Essas ferramentas também são importantes para classificar a doença em questão em duas síndromes. Uma delas é a Síndrome do Sofrimento Pós-Prandial (PDS) com plenitude pós-prandial e saciedade precoce. A outra é a Síndrome da Dor Epigástrica (SEP) com dor epigástrica e queimação epigástrica. A SEP independe da relação com as refeições (Fan \& Talley, 2017). Também pode haver sobreposição entre as síndromes e segundo Burns et al. (2019) pode corresponder até $66 \%$ da prática clínica.

O tratamento considera os vários fatores etiológicos envolvidos. Nele está incluída a erradicação da H. pylori, recomendada em pacientes positivos para esta bactéria. Também inclui a supressão de ácido que usa medicamentos inibidores da bomba de prótons, os quais diminuem a expressão do gene da eotaxina. A Procinética também é uma forma de tratamento e ela ajuda na acomodação gástrica e no esvaziamento gástrico. Os Antidepressivos também estão englobados como segunda ou terceira linha de tratamento. Das terapias alternativas merecem destaque a fitoterápica e a probiótica (Fan \& Talley, 2017).

Embora alguns estudos tenham contribuído para a elucidação do viés imune na DF, ainda há dificuldades em definir os processos da resposta imune nessa doença, mais especificamente uma descrição única, e consequentemente as repercussões que ela traz ao paciente. Segundo Burns et al. (2019) a disparidade na literatura quanto ao assunto e a heterogeneidade das FGIDs dificultam o esclarecimento das condições imunes envolvidas. Portanto, o presente estudo tem por objetivo avaliar, em pacientes com Dispepsia Funcional, qual o risco de repercussões imunes.

\section{Metodologia}

O presente estudo se trata de uma Revisão Sistemática de Etiologia e Fator de Risco, de Estudos de Coorte, que por estarem relacionados ao desenvolvimento de algum evento/patologia se tornam importantes para determinar a relação exposição-doença, hipóteses, incidências e associações entre variáveis (Sousa \& Santos, 2016). Inicialmente, foi utilizada a estratégia PO (paciente e outcomes/desfecho), em que a população de interesse foi composta por pacientes com dispepsia funcional e o desfecho relacionou-se com as repercussões imunes. Na busca bibliográfica para construção do estudo, foi formulada a questão do acrômio PO: "Em pacientes com dispepsia funcional, qual o risco de repercussões imunes?".

Realizou uma busca bibliográfica e transversal através de publicações de artigos científicos em meios eletrônicos nas seguintes bases de dados incluídas com fontes de pesquisa: Biblioteca Virtual em Saúde (BVS) e PubMed. Quanto aos critérios de inclusão para a seleção dos estudos, consideraram-se as publicações de qualquer ano, nacionais e internacionais, estudos do tipo Estudos de Coortes e Transversais, estudos que abordam as repercussões imunes em pacientes com dispepsia funcional e estudos disponibilizados online na forma de artigo completo. Excluíram-se caso controle, ensaios clínicos randomizados, estudo de acurácia e estudos que não responderam à questão da pesquisa.

Utilizaram-se os Descritores em Ciências da Saúde (DeCS) no idioma inglês: "Dyspepsia", "Immune System”. Tais DeCS foram associados a partir do operador lógico boleano " $A N D$ ".

Como recomendado (Donato \& Donato, 2019), para eleger os estudos foi feita uma avaliação em duas etapas, cada uma delas por 2 autores e ambas de maneira independente. O primeiro autor participou de todas elas. Na primeira etapa foram selecionados os artigos de acordo com o título e resumo, ou seja, eliminaram-se os artigos duplicados, e seria elegível para seguir em análise se os dois revisores considerassem o artigo adequado. Na segunda etapa, os artigos selecionados foram lidos 
por completo e aprovados mediante consenso entre os revisores. Não houve discordância entre os coautores nas duas etapas.

A Figura 1 apresenta o fluxograma dos artigos que foram incluídos. As buscas nas bases de dados resultaram em 32 artigos, dos quais cinco enquadraram-se nos critérios de inclusão e foram usados para desenvolver o presente estudo.

Figura 1: Fluxograma representativo da seleção do material da revisão.

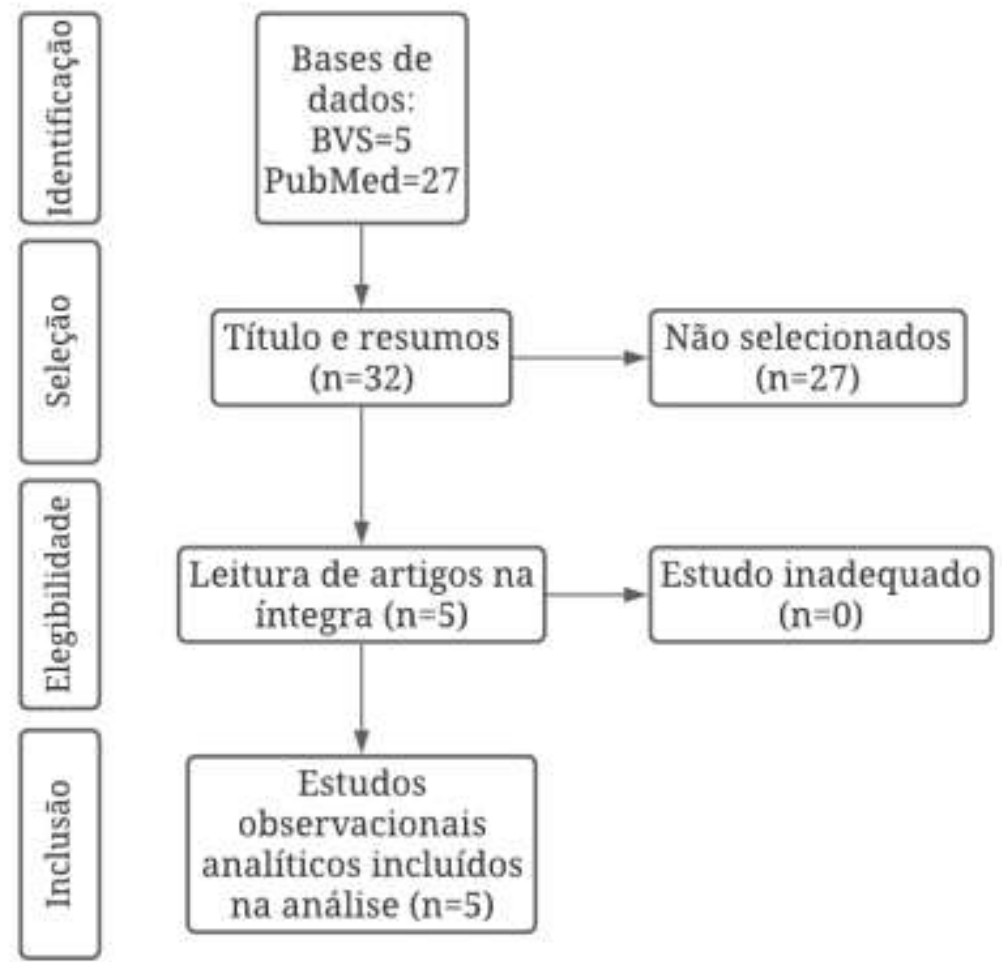

Fonte: Dados de pesquisa (2021).

Para avaliar a qualidade de evidência produzida pelos artigos selecionados usou-se o método desenvolvido recentemente, chamado Grading of Recomendations Assessment, Developing and Evaluation (GRADE). Classifica a evidência em quatro níveis: alto, moderado, baixo ou muito baixo (Galvão \& Pereira, 2015). O nível alto de evidência significa que há grande prevalência do efeito observado na produção científica em questão.

\section{Resultados}

No Quadro 1, observa-se a distribuição dos estudos selecionados quanto ao país, ano de produção, tipo de estudo, nível de evidência, base de dados em que foi encontrado e objetivo principal. As produções se tratam de Estudos de Coortes e Transversais, e foram desenvolvidos em dois países principais: Austrália e Bélgica. Dois deles foram produzidos na última década. 
Quadro 1: Caracterização geral dos artigos selecionados para compor a Revisão Sistemática. Patos, 2021.

\begin{tabular}{|l|l|l|l|l|l|}
\hline \multicolumn{1}{|c|}{ Autores } & País & Ano & $\begin{array}{c}\text { Tipo de } \\
\text { estudo }\end{array}$ & $\begin{array}{c}\text { Base de } \\
\text { dados }\end{array}$ & \multicolumn{1}{|c|}{ Objetivo principal } \\
\hline $\begin{array}{l}\text { Jones et } \\
\text { al. (2014) }\end{array}$ & Austrália & 2014 & $\begin{array}{l}\text { Estudo de } \\
\text { Coorte }\end{array}$ & BVS & $\begin{array}{l}\text { Investigar se os dados se traduzem na prática clínica examinar as conexões } \\
\text { da perspectiva dos FGIDs para determinar se a atopia e os FGIDs estão } \\
\text { conectados por meio de transtornos de humor. }\end{array}$ \\
\hline $\begin{array}{l}\text { Jones et } \\
\text { al. (2020) }\end{array}$ & Austrália & 2019 & $\begin{array}{l}\text { Estudo de } \\
\text { Coorte }\end{array}$ & PUBMED & $\begin{array}{l}\text { Identificar os fatores do início da vida associados ao desenvolvimento de dor } \\
\text { abdominal em crianças (2 a 12 anos de idade), tendo em vista que ela é uma } \\
\text { característica central em distúrbios funcionais. }\end{array}$ \\
\hline $\begin{array}{l}\text { Kindt et } \\
\text { al. } \\
(2009 a)\end{array}$ & Bélgica & 2009 & $\begin{array}{l}\text { Estudo de } \\
\text { Coorte }\end{array}$ & BVS & $\begin{array}{l}\text { Comparar sinais de inflamação e hiperplasia de células enteroendócrino nas } \\
\text { biópsias duodenais em Dispepsia Funcional Pós-Infeccioso (DF- PI) vs } \\
\text { Dispepsia Funcional de início não especificado (DF - NE) }\end{array}$ \\
\hline $\begin{array}{l}\text { Kindt et } \\
\text { al. } \\
(2009 b)\end{array}$ & Bélgica & 2009 & $\begin{array}{l}\text { Estudo de } \\
\text { Coorte }\end{array}$ & PUBMED & $\begin{array}{l}\text { Avaliar as respostas imunes celulares e humorais em (i) FGIDs, em } \\
\text { comparação com indivíduos saudáveis e (ii) FGIDs de início agudo vs não } \\
\text { especificado. }\end{array}$ \\
\hline $\begin{array}{l}\text { Luzza et } \\
\text { al. (1995) }\end{array}$ & Itália & 1995 & $\begin{array}{l}\text { Estudo } \\
\text { Transversal }\end{array}$ & PUBMED & $\begin{array}{l}\text { Definir o padrão isotípico do Helicobacter pylori sérico, salivar, gástrico e } \\
\text { retal respostas de anticorpos específicos e para explorar seus inter- } \\
\text { relacionamentos. }\end{array}$ \\
\hline
\end{tabular}

Fonte: Dados de pesquisa (2021).

No Quadro 2, estão descritos os dados relacionados às caracterizações metodológicas dos estudos relacionados ao grupo analisado, seleção dos pacientes, modo de realização e modo de avaliação.

Quadro 2: Caracterização metodológica dos artigos selecionados para compor a Revisão Sistemática. Patos, 2021.

\begin{tabular}{|c|c|c|c|c|}
\hline $\begin{array}{l}\text { Autores/ } \\
\text { Ano }\end{array}$ & Grupo analisado & Seleção dos pacientes & Modo de realização & Modo de avaliação \\
\hline $\begin{array}{l}\text { Jones et } \\
\text { al. } \\
(2014)\end{array}$ & $\begin{array}{l}\text { Pacientes com distúrbios } \\
\text { gastrointestinais funcionais } \\
\text { (FGIDs) a partir de } 30.000 \\
\text { registros de prontuários } \\
\text { médicos durante um } \\
\text { período mínimo de } 5 \text { anos. }\end{array}$ & $\begin{array}{l}\text { Os critérios de inclusão foram } \\
\text { diagnósticos de GP de Síndrome } \\
\text { do Intestino Irritável, Dispepsia } \\
\text { Funcional ou Constipação } \\
\text { Idiopática Crônica, pelo menos } \\
5 \text { anos de acompanhamento do } \\
\text { prontuário médico e um } \\
\text { indicador de qualidade de } \\
\text { prontuário do paciente aceitável. }\end{array}$ & $\begin{array}{l}\text { Foi realizada uma leitura dos } \\
\text { códigos diagnósticos indicativos } \\
\text { desses distúrbios, bem como de } \\
\text { termos adicionais que possam ser } \\
\text { remetidos a eles como uma } \\
\text { evidência direta. Já para outras } \\
\text { doenças relacionadas, como } \\
\text { doenças atópicas, ansiedade e } \\
\text { depressão. }\end{array}$ & $\begin{array}{l}\text { A abordagem estatística buscou } \\
\text { evidenciar a prevalência de } \\
\text { certas condições atópicas nas } \\
\text { FGIDs do que em pacientes sem } \\
\text { FGID. Para isso, foram } \\
\text { utilizados três modelos de } \\
\text { regressão logística } \\
\text { incondicional para cada } \\
\text { desfecho de doença atópica, } \\
\text { com um intervalo de confiança } \\
\text { de } 95 \% \text {. }\end{array}$ \\
\hline $\begin{array}{l}\text { Jones } e t \\
\text { al. } \\
(2020)\end{array}$ & $\begin{array}{l}1781 \text { crianças recrutadas } \\
\text { ao nascimento para o } \\
\text { estudo All Babies in } \\
\text { Southeast Sweden, } \\
\text { nascidas de } 1 \text { de outubro } \\
\text { de } 1997 \text { a } 31 \text { de outubro de } \\
1999 \text { na região sudeste da } \\
\text { Suécia. }\end{array}$ & $\begin{array}{l}\text { Foram incluídas crianças de } 2 \text { a } \\
12 \text { anos de idade. }\end{array}$ & $\begin{array}{l}\text { As famílias das crianças } \\
\text { responderam a perguntas sobre } \\
\text { dor abdominal e fatores de risco } \\
\text { ao nascimento, } 1 \text { ano, } 2,5 \text { anos, } 5 \\
\text { anos, } 8 \text { anos e } 10 \text { a } 12 \text { anos. }\end{array}$ & $\begin{array}{l}\text { Analisaram-se os fatores } \\
\text { psicológicos, sociais e } \\
\text { relacionados às alergias. Com } \\
\text { destaque para os sociais que } \\
\text { podem influenciar no } \\
\text { desenvolvimento do sistema } \\
\text { imunológico. Avaliaram-se os } \\
\text { fatores de risco para o } \\
\text { desenvolvimento de dor } \\
\text { abdominal através de modelos } \\
\text { de curva de crescimento latente. }\end{array}$ \\
\hline $\begin{array}{l}\text { Kindt et } \\
\text { al. } \\
\text { (2009a) }\end{array}$ & $\begin{array}{l}\text { Pacientes com distúrbio } \\
\text { gastrointestinal funcional } \\
\text { (FGID) (68) e pacientes } \\
\text { saudáveis (32). E pacientes } \\
\text { com FGID de início agudo } \\
\text { e os não especificados. }\end{array}$ & $\begin{array}{l}\text { Os saudáveis não tinham } \\
\text { sintomas ou uma história de } \\
\text { doença gastrointestinal, nem } \\
\text { estavam tomando qualquer } \\
\text { medicamento. Excluíram-se os } \\
\text { casos de transtorno psiquiátrico } \\
\text { que influenciasse a percepção } \\
\text { dos sintomas. }\end{array}$ & $\begin{array}{l}\text { Após a estimulação com } \\
\text { fitohemaglutinina e anti-CD28 } \\
\text { ou lipopolissacarídeo (LPS), } \\
\text { caracterizou-se em linha de base } \\
\text { a produção de citocinas } \\
\text { linfocíticas e monocíticas. }\end{array}$ & $\begin{array}{l}\text { Comparou-se as concentrações } \\
\text { séricas de IL- } 6 \text { e IL-10, e } \\
\text { avaliou-se o imunofenótipo } \\
\text { usando classificador de células } \\
\text { ativadas por fluorescência }\end{array}$ \\
\hline $\begin{array}{l}\text { Kindt et } \\
\text { al. } \\
(2009 b)\end{array}$ & $\begin{array}{l}\text { Pacientes recrutados no } \\
\text { mesmo centro de } \\
\text { atendimento terciário, em } \\
\text { UZ Gasthuisberg, Leuven, } \\
\text { na Bélgica, com distúrbios }\end{array}$ & $\begin{array}{l}\text { Os pacientes foram questionados } \\
\text { se seus sintomas haviam surgido } \\
\text { de repente. Além disso, foi } \\
\text { perguntado se o início foi } \\
\text { imediatamente precedido por }\end{array}$ & $\begin{array}{l}\text { Como parte do estudo, os } \\
\text { pacientes, além de serem } \\
\text { questionados sobre o início de } \\
\text { seus sintomas, também foram } \\
\text { submetidos a teste de }\end{array}$ & $\begin{array}{l}\text { As diferenças entre os pacientes } \\
\text { DF-PI e DF-NE em números } \\
\text { foram comparados pelo t-teste } \\
\text { de Student não pareado ou teste } \\
\text { de Wilcoxon quando }\end{array}$ \\
\hline
\end{tabular}




\begin{tabular}{|c|c|c|c|c|}
\hline & $\begin{array}{l}\text { gastrointestinais funcionais } \\
\text { que foram subdivididos } \\
\text { naqueles que tiveram } \\
\text { algum quadro infeccioso } \\
\text { antes de desenvolverem } \\
\text { DF e aqueles que não } \\
\text { tiveram nenhum quadro } \\
\text { infeccioso antes de } \\
\text { apresentarem sintomas de } \\
\text { DF. }\end{array}$ & $\begin{array}{l}\text { sintomas sugestivos de uma } \\
\text { inflamação gastrointestinal } \\
\text { aguda (febre, diarreia, dores } \\
\text { musculares, vômitos e náuseas). } \\
\text { Apenas aqueles pacientes que } \\
\text { relataram um início agudo e } \\
\text { respondem a pelo menos um } \\
\text { sintoma foram considerados } \\
\text { pacientes presumidos com DF- } \\
\text { PI. Os demais sujeitos foram } \\
\text { categorizados como DF-NE. }\end{array}$ & $\begin{array}{l}\text { esvaziamento gástrico para } \\
\text { sólidos e um barostato gástrico. } \\
\text { Biópsias foram feitas, em média } \\
13 \text { meses após o evento } \\
\text { infeccioso, para contagem de } \\
\text { linfócitos intra-epiteliais por } \\
\text { vilosidade e CA positivo por } \\
\text { criptas em amostras } \\
\text { separadamente para investigação } \\
\text { do número de células } \\
\text { imunorreativas presentes nas } \\
\text { vilosidades sob o epitélio } \\
\text { investigado. }\end{array}$ & $\begin{array}{l}\text { aplicável.A presença de intra- } \\
\text { epitelial, intravilar e o número } \\
\text { de CD3, Células CD4, CD8 e } \\
\text { CD68 + por criptas, e a média } \\
\text { número de células positivas } \\
\text { para cromogranina A (CA) por } \\
\text { vilosidades foram comparadas. }\end{array}$ \\
\hline $\begin{array}{l}\text { Luzza et } \\
\text { al. } \\
(1995)\end{array}$ & $\begin{array}{l}\text { O primeiro grupo de } \\
\text { pacientes consistia em } 79 \\
\text { pacientes ( } 42 \text { homens, } 27 \\
\text { mulheres; idade média: } 48 \\
\pm 12 \text { ) que se submeteram a } \\
\text { endoscopia digestiva alta. } \\
\text { O segundo grupo de } \\
\text { pacientes consistia em } 28 \\
\text { pacientes (17 homens, } 11 \\
\text { mulheres; idade média: } 46 \\
\pm 12 \text { ) submetido a } \\
\text { sigmoidoscopia para } \\
\text { intestino funcional } \\
\text { desordens. }\end{array}$ & $\begin{array}{l}\text { Selecionaram pacientes com } \\
\text { sintomas dispépticos de ambos } \\
\text { os sexos e faixas de idade } \\
\text { variadas. }\end{array}$ & $\begin{array}{l}\text { Em todos os pacientes, amostras } \\
\text { de soro e de saliva não } \\
\text { estimuladas foram coletados. } \\
\text { Nos } 79 \text { pacientes do primeiro } \\
\text { grupo e nos } 22 \text { gastroscopiado do } \\
\text { segundo grupo, } 4 \text { biópsias antrais } \\
\text { foram feitas de cada paciente. } \\
\text { Quatro biópsias retais adicionais } \\
\text { foram retiradas de cada paciente } \\
\text { do segundo grupo. Amostras de } \\
\text { soro e saliva foram } \\
\text { centrifugadas, codificadas e } \\
\text { armazenado a - } 20^{\circ} \mathrm{C} \text { até o teste. } \\
\text { Antral e retal as amostras de } \\
\text { biópsia foram homogeneizadas } \\
\text { separadamente em gelo usando } \\
\text { um homogeneizador de tecido } \\
\text { (Ystral, GmbH, Dottingen, } \\
\text { Alemanha). Os homogenados } \\
\text { eram fiados (600 x g por } 20 \text { min } \\
\text { a } 4 \text { "C), codificado e armazenado } \\
\text { a - } 80^{\circ} \mathrm{C} \text { até o teste. H.pylori } \\
\text { específico IgG e IgA foram } \\
\text { medidos em cada amostra de } \\
\text { soro, saliva e mucosa (gástrica e } \\
\text { / ou retal) homogeneizando por } \\
\text { ELISA direto. }\end{array}$ & $\begin{array}{l}\text { Analisou-se a medição de IgG e } \\
\text { IgA específica de H. pylori } \\
\text { através de uma sonicação de } \\
\text { uma cepa inteira de H. pylon } \\
\text { que foi usada como fonte de } \\
\text { antígeno.Todas as amostras } \\
\text { foram processadas no mesmo } \\
\text { ensaio ELISA. A positividade } \\
\text { do H. pylori sérico foi definida } \\
\text { usando um pool de } 100 \text { soros de } \\
\text { controle negativo como } \\
\text { referência para determinações } \\
\text { de IgG que deram uma } \\
\text { sensibilidade e uma } \\
\text { especificidade de } 94 \% \text { e } 95 \% \text {, } \\
\text { respectivamente. Os resultados } \\
\text { foram expressos como média } \\
\text { óptica densidade + S.D. O teste } \\
\text { t de Student foi usado para } \\
\text { análise dos dados. }\end{array}$ \\
\hline
\end{tabular}

Fonte: Dados de pesquisa (2021).

No Quadro 3, evidenciam-se os resultados dos Estudos de Coortes e Transversal, bem como as principais conclusões obtidas. 
Quadro 3: Principais Resultados. Patos, 2021.

\begin{tabular}{|c|c|}
\hline Autores/Ano & Principais Resultados \\
\hline $\begin{array}{l}\text { Jones et al. } \\
\text { (2014) }\end{array}$ & $\begin{array}{l}\text { As condições atópicas foram encontradas em excesso entre } \\
\text { todos os grupos de FGID considerados quando comparados } \\
\text { com os controles. Nos grupos com IBS sozinho (OR }=1,43 \text {, } \\
1,29-1,58) \text {, FD sozinho (OR }=1,41,1,26-1,58) \text { e aqueles com } \\
\text { múltiplos FGIDs (OR }=1,92,1,75-2,12 \text { ) houve elevada } \\
\text { prevalência de asma em comparação com os controles sem um } \\
\text { FGID. Entre os distúrbios, o excesso foi geralmente mais alto } \\
\text { entre os pacientes com diagnóstico de múltiplos FGIDs (rinite / } \\
\text { febre do feno OR = } 3,74,3,32-4,20 \text {; conjuntivite OR }=3,00 \text {, } \\
2,49-3,62) \text { e foi apenas parcialmente explicado por uma } \\
\text { associação comum entre ambos os FGIDs e condições atópicas } \\
\text { com transtornos de humor, embora não para todas as } \\
\text { combinações atópicas / FGID (rinite / febre do feno OR }=2,60 \text {, } \\
2,29-2,96 \text {, conjuntivite OR }=2,34,1,90-2,87 \text { ). }\end{array}$ \\
\hline $\begin{array}{l}\text { Jones et al. } \\
\text { (2020) }\end{array}$ & $\begin{array}{l}\text { Registrou-se dor abdominal em } 1.698 \text { crianças em todas as } 4 \\
\text { faixas de idades consideradas. O maior aumento linear na } \\
\text { prevalência de dor abdominal foi aos } 12 \text { anos, com } 11,1 \% \text {. Nos } \\
\text { fatores psicossociais, destacou-se o temperamento da criança } \\
\text { aos } 2 \text { anos. Houve evidência comum de eczema, presente em } \\
\text { um quarto da amostra. Nas outras formas de parto, excluindo o } \\
\text { normal/vaginal, observou-se diminuição no crescimento da } \\
\text { prevalência de dor abdominal. }\end{array}$ \\
\hline
\end{tabular}

Kindt et al. $\quad$ Dos 23 pacientes que tinham Dispepsia Funcinal, 14 possuíam (2009a) alguma alergia. 6 deles relataram início agudo dos sintomas. Em relação à IL-6 plasmática basal, não se observou diferença. Mas após a estimulação mitogênica, a produção linfocítica de IL-5 e IL-13 aumentou significativamente nos pacientes comparado ao grupo controle, enquanto a produção de INF-c diminuiu. Após a estimulação, diminuiu a produção de IL-10 nos pacientes em relação ao controle, com destaque para os pacientes com Dispepsia Funcional. Após a estimulação por lipopolissacarídeos, 22 dos 23 pacientes com Dispepsia Funcional mostraram níveis suprimidos de IL-12. Não se encontrou diferença entre controles e pacientes e entre os subgrupos de pacientes no que diz respeito aos marcadores CD. Também não foi encontrada diferença entre controles e pacientes quanto ao número de LBs, células NK, células CD4+ e CD8+. Quando os sintomas eram de início agudo constatouse aumento na concentração plasmática de IL-10. Quanto à IL6 não houve diferença. Nos pacientes com Dispepsia Funcional a estimulação com LPS aumentou significativamente a expressão de TNF-alfa nos que tiveram início agudo dos sintomas, em comparação com os que tiveram início não especificado. Os que tiveram início agudo dos sintomas apresentaram maior número de células CD3+ CD45RA+ CD45RO+.

Kindt et al. Amostras duodenais de 24 pacientes (15 mulheres, 12 PI-FD) (2009b) estavam disponíveis para avaliação patológica. Contudo, apenas 11 e nove amostras estavam disponíveis para análise de CD4, CD8 e CD68 em U-FD e PI-FD respectivamente. Os pacientes tinham $38,8 \pm 3,2$ anos e eram pesados $59,1 \pm 3,4 \mathrm{~kg}$ com um índice de massa corporal de $20,8 \pm 1,1 \mathrm{~kg} \mathrm{~m})$. Sem diferenças nas características demográficas foram observados entre os dois grupos. Houve uma redução significativa no número de células $\mathrm{CD} 4+$ localizadas dentro das vilosidades $(0,5 \pm 0,2$ vs $2,7 \pm 0,7, \mathrm{P}=0,01)$ e no número de células $\mathrm{CD} 4+$ por cripta $(0,52 \pm 1,6$ vs $1,22 \pm 2,18, \mathrm{P}=0,04)$ em pacientes com DF-PI. Agregados focais de células CD4 +estavam presentes em uma biópsia de 11 pacientes DF-NE, enquanto este foi o caso para três das nove biópsias de pacientes com DF-PI. Finalmente, foi detectado um aumento no número de células CD68 + por cripta em pacientes DF-PI $(0,64 \pm 0,13$ vs $0,40 \pm 0,05, P=0,03)$, mas o número de linfócitos intravilares foram semelhantes $(2,9 \pm 0,7$ vs $2,7 \pm 0,3$, ns $)$. Não foi encontrado nenhuma diferença na $\mathrm{CE}$ e Contagens IEL conforme revelado pela coloração CD3 + e CA. Contudo,

Conclusão

A síndrome do intestino irritável, dispepsia funcional e constipação compartilham uma associação com atopia que é apenas parcialmente explicada por meio de uma conexão comum com transtornos de humor. Esses dados têm implicações importantes para a compreensão tanto da fisiopatologia dos distúrbios gastrointestinais funcionais quanto do desenvolvimento de novos tratamentos.

Não houve confirmação de repercussões imunológicas, tendo em vista que o sistema imunológico das crianças está em desenvolvimento. Mesmo esse sendo um ponto explorado por estudos anteriores. Mas sabe-se que os fatores como modalidade de parto, duração da amamentação, número de animais de estimação e educação materna e paterna influenciam na construção do sistema imunológico do indivíduo e podem fazer com que este venha a desenvolver um Distúrbio Gastrointestinal Funcional.

Observou-se uma correlação significativa entre ambos os escores de ansiedade e depressão e IL5 estimulado, IL-13 e níveis de TNF para todo o grupo. Encontrou-se uma fraca correlação entre os níveis basais de IL-10 no plasma e escores de depressão. Mudança na produção de citocinas do tipo Th1 (IFN-c) para do tipo Th2 (IL-5 e IL-13), mesmo com a diminuição de IL-10. Há produção aumentada de IL-5 e IL-13 em pacientes com Dispepsia Funcional. Por outro lado, há diminuição de IL-12, IL-10, IFN-c. Na Dispepsia Funcional houve significativa diminuição de IL-10. Na fase aguda da Dispepsia Funcional, identificou-se aumento de IL-10 e, após estimulação, houve diminuição de TNF-a. Transição de células $\mathrm{T}$ virgens para células $\mathrm{T}$ de memória pelo aumento de alguns marcadores imunológicos.

No estudo foi encontrado um esvaziamento gástrico significativamente atrasado e uma tendência para acomodação gástrica prejudicada em Dispepsia Funcional Pós-Infecciosa. As alterações inflamatórias demonstradas neste estudo não correspondem às alterações observadas anteriormente no IBS. Não há dados sobre alterações pós-inflamatórias simultaneamente envolvendo o TGI superior e inferior. Avançar estudos em biópsias retiradas do duodeno e reto são necessários para resolver este problema. Foi demonstrado também que pacientes identificados como DF-PI são caracterizados por um padrão de sintoma específico e fisiopatológico diferentes neste grupo de pacientes. Resolver esse problema exigiria um acompanhamento prospectivo de biópsias e sintomas em pacientes que sofreram de uma infecção gastrointestinal aguda. $\mathrm{O}$ estudo mostrou a persistência da presença dos agregados de células após um episódio infeccioso, indicando o atraso ou a incapacidade do sistema imunológico de terminar a resposta inflamatória apesar da adequada remoção do patógeno causador. 


\begin{tabular}{|c|c|c|}
\hline & $\begin{array}{l}\text { descobrimos que PI-FD é caracterizado pela presença de } \\
\text { agregados focais de células } \mathrm{T} \text { CD } 8+\text {, células CD } 4 \\
\text { diminuidas e aumento da contagem de macrófagos em torno } \\
\text { das criptas que persistem vários meses após a crise aguda } \\
\text { insulto. }\end{array}$ & \\
\hline $\begin{array}{l}\text { Luzza et al. } \\
(1995)\end{array}$ & $\begin{array}{l}\text { No primeiro grupo, } 74 \text { pacientes tiveram sorologia positiva } \\
\text { para H.pylori, conforme indicada no soro, e no segundo grupo } \\
\text { dos } 28 \text { pacientes, em } 26 \text { foram detectados H.pylori sorologia } \\
\text { positiva. O padrão isotípico de anticorpos específicos de H. } \\
\text { pylon pareceu diferir no soro, salivar, gástrico e retal nível da } \\
\text { mucosa. Os títulos de IgG de H. pylori no soro eram maiores } \\
\text { do que os de IgA sérica específica. Pelo contrário, em amostras } \\
\text { de saliva H.pylori os títulos de IgA foram maiores do que os } \\
\text { títulos de IgG específicos. Nos homogenatos gástricos, os } \\
\text { títulos específicos de IgG e IgA foram semelhantes. H.pylori } \\
\text { IgG específica foram detectáveis em homogenatos reta1, mas } \\
\text { nenhuma ou muito baixa IgA específica de H. pylori foi } \\
\text { encontrada no mesmo material. Além disso, nenhuma diferença } \\
\text { foi encontrada em H. pylori IgG e IgA no soro, saliva e } \\
\text { homogenatos gástricos entre úlcera duodenal e pacientes com } \\
\text { dispepsia não ulcerosa. }\end{array}$ & $\begin{array}{l}\text { Tornou-se claro que H. pylori desempenha um papel etiológico } \\
\text { na gastrite crônica, doença de úlcera péptica, e possivelmente } \\
\text { no câncer gástrico. Só recentemente foi apreciado que a } \\
\text { resposta imune da mucosa gástrica pode representar um } \\
\text { mecanismo patogenético principal nas doenças associadas ao } \\
\text { H.pylori. Os dados do presente estudo indicam que, em } \\
\text { pacientes infectados com H. pylori, o sistema imunológico } \\
\text { específico a resposta é a seguinte: (1) envolve o sistema } \\
\text { imunológico secretor; (2) é paralelo à IgA salivar específica; (3) } \\
\text { não diferenciar úlcera duodenal de pacientes com dispepsia não } \\
\text { ulcerosa; e (4) não ocorre no intestino grosso. }\end{array}$ \\
\hline
\end{tabular}

Fonte: Dados de pesquisa (2021).

Os fatores que influenciam no nível de evidência e qualidade das evidências, de acordo com o sistema GRADE, são abordados no Quadro 4. Apenas um estudo possui baixa qualidade, o restante foi classificado como moderados.

Quadro 4: Avaliação da qualidade dos estudos selecionados nesta pesquisa.

\begin{tabular}{|l|c|c|c|c|c|c|}
\hline Autores & $\begin{array}{c}\text { Limitações } \\
\text { Metodológicas }\end{array}$ & Inconsistência & $\begin{array}{c}\text { Evidência } \\
\text { indireta }\end{array}$ & Imprecisão & $\begin{array}{c}\text { Viés de } \\
\text { publicação }\end{array}$ & Qualidade \\
\hline Jones et al. (2014) & Não há & Não há & Não há & Não há & Presente & Moderada \\
\hline Jones et al. (2020) & Presente & Não há & Não há & Não há & Não há & Moderada \\
\hline Kindt et al. (2009a) & Não há & Não há & Não há & Não há & Presente & Moderada \\
\hline Kindt et al. (2009b) & Presente & Presente & Presente & Não há & Presente & Baixa \\
\hline Luzza et al. (1995) & Não há & Não há & Presente & Não há & Não há & Moderada \\
\hline
\end{tabular}

Fonte: Dados de pesquisa (2021).

\section{Discussão}

Desde a primeira infância, o sistema imunológico GI de um indivíduo evolui em conjunto com seu microbioma, resultando em funções conjuntas, que vão desde a proteção de superfícies mucosas da invasão patogênica e reconhecimento de moléculas próprias até a estimulação de uma resposta imunológica mediada por células. As células T reguladoras são mediadores imunológicos da homeostase do trato GI, e a depleção ou ausência desses mediadores resulta em inflamação no trato GI. Foi reconhecido que a capacidade das células T reguladoras de manter a homeostase está envolvida na supressão das células T gama delta $(\gamma \delta)$, que se acredita ligar as respostas imunes inatas e adaptativas (Wu \& Wu, 2012).

Não se sabe se a redução observada na diversidade e o aumento da instabilidade da microbiota ao longo do tempo na doença gastrointestinal são causais ou consequentes, mas pode sugerir uma situação em que a regulação homeostática é desafiada pela expansão oportunista de patobiontes. O domínio recém-descoberto de tais espécies pode provocar o sistema imunológico e potencializar doenças. Neste cenário hipotético, o reconhecimento de componentes bacterianos por receptores de reconhecimento de padrões inatos, inicia a ativação da sinalização intracelular para resultar na secreção e ativação de citocinas inflamatórias, como IL-1 $\beta$ e IFNs. Essas moléculas sinalizam para recrutamento e ativação de populações de células efetoras, resultando em inflamação de baixo grau, como a observada em DF (Collins, 2014). 
Analisando a relação entre os resultados dos Estudos de Coorte e Transversal selecionado e as conclusões dos autores, há relação da Dispepsia Funcional com a atopia, principalmente em pacientes que possuíam mais de uma síndrome disfuncional. Demonstrou-se, mediante estimulação mitogênica, o aumento de citocinas como IL-5 e IL-13, e diminuição de IL-10 e IL-12. Além disso, mostrou-se relação entre quadros infecciosos e o posterior desenvolvimento da Dispepsia Funcional, encontrando-se diminuição de células CD4+, aumento das células CD68+ e aumento do número de macrófagos persistentes após um episódio infeccioso (Kindt et al, 2009a; Kindt, Tertychnyy, de Hertogh, Geboes \& Tack, 2009b).

Também se notou que fatores associados ao desenvolvimento do sistema imunológico, mais especificamente na infância, como modalidade de parto, duração da amamentação, número de animais de estimação e educação materna e paterna influenciam na construção do sistema imunológico e podem contribuir para o surgimento de algum Distúrbio Gastrointestinal Funcional, como a Dispepsia Funcional (Koloski et al, 2015; Jones, Faresjö, Beath, Faresjö \& Ludvigsson, 2020).

Destarte, pela análise dos resultados descritos em ambas as amostras estudadas por Kindt et al. (2009a; 2009b) foi analisado as repercussões imunológicas da DF nos pacientes portadores desta patologia, entretanto houveram algumas divergências nas amostras coletadas.

Enquanto no primeiro estudo de 2009, a imunofenotipagem A, em análise da porcentagem e dos números absolutos de $\mathrm{CD} 3+\mathrm{CD} 45 \mathrm{RA}+$, verificou-se que as células $\mathrm{CD} 45 \mathrm{RO}+$ foram significativamente maiores em pacientes que relataram um início agudo de seus sintomas. Nenhuma diferença foi observada na quantidade de linfócitos, células B, células NK, nem Células CD4 + ou CD8 + (Kindt et al., 2009a).

Contudo, no estudo publicado alguns meses depois, ao diferenciar ainda mais essas células $\mathrm{T}$, percebeu-se que os Linfócitos Intraepiteliais consistiam quase exclusivamente em Células CD8 +. No entanto, o número de intra-epiteliais Células CD8 + (23,6 $\pm 3,7$ vs 30,1 $\pm 6,2$, ns), o número de células CD8 + intravilares $(3,9 \pm 0,7$ vs 5,6 $\pm 1,3$, ns) ou o número de células CD8 + por cripta ( $1,43 \pm 0,21$ vs $2,11 \pm 0,21$, ns) não diferiu significativamente entre ambos os grupos. Confirmou-se a presença de focal agregados de células CD8 + em cinco de nove DF-PI pacientes, mas nenhum em DF-NE (Fischer exato $\mathrm{P}=$ $0,009)$. Houve também uma redução significativa no número de Células CD4 + localizadas dentro das vilosidades $(0,5 \pm 0,2$ vs 2,7 $\pm 0,7, \mathrm{P}=0,01)$ e no número de células CD4 + por cripta $(0,52 \pm 1,6$ vs $1,22 \pm 2,18, \mathrm{P}=0,04)$ em pacientes DF-PI. Por fim, foi detectado um aumento no número de células CD68 + por cripta em pacientes DF-PI $(0,64 \pm 0,13$ vs $0,40 \pm 0,05, P=$ 0,03) (Kindt et al., 2009b).

Apesar das divergências nas amostras dos estudos, houve pontos de consonância relativos às caracterizações dos linfócitos e macrófagos. Em comparação com indivíduos saudáveis, a expressão estimulada de IL-5 e IL-13 por linfócitos foi aumentada em pacientes que sofrem de SII, DF e NCCP. Por outro lado, a IL-12 monocítica estimulada e as expressões linfocíticas de IL-10 foram reduzidas em SII e DF, enquanto a expressão de IFN-c também foi reduzida em DF pacientes. No outro estudo analisado, agregados basais estavam presentes em sete dos 12 DF-PI e três de 12 pacientes DF-NE $(P=0,1)$. Intra-epitelial aglomerados de linfócitos foram detectados em seis de 12 DF-PI e dois dos 12 pacientes DF-NE $(\mathrm{P}=0,08)$. Nenhum dos 12 Os pacientes DF-NE apresentaram agregados focais de T células, enquanto estas estavam presentes em cinco dos 12 DF-PI pacientes ( $\mathrm{P}=0,01)$; também houve aumento das contagens dos macrófagos em torno das criptas (Kindt et al., 2009a; Kindt, 2009b).

Em um novo estudo que visa avaliar se a ativação imune anormal ocorre em DF, aumento da homing intestinal CD4 + $\alpha 4 \beta 7$ + CCR9 + linfócitos e níveis elevados de citocinas, incluindo fator de necrose tumoral- $\alpha$, foram detectados na circulação periférica no DF. As alterações foram significativamente associadas a uma maior intensidade dos sintomas e, notavelmente, ao retardo do esvaziamento gástrico. Outros dados indicam que a microbioma duodenal é anormal em DF com uma possível predominância na flora oral e uma ligação entre a carga bacteriana e os sintomas (Liebregts et al, 2011; Talley, Holtmann \& Walker, 2015). 
Tais descobertas sugerem que a inflamação duodenal é uma característica de pacientes com DF e da desregulação imunológica adicional. A microbiota duodenal pode desempenhar um papel patogênico importante na condução de anormalidades funcionais na DF.

Os dados coletados nesses estudos de coorte corroboram para a solidificação da teoria que atribui a uma infecção gastrointestinal o papel desencadeador da DF e também influencia no quadro sintomatológico no paciente. A infecção gastrointestinal anterior é agora um fator de risco estabelecido para SII e DF. No Estudo de saúde em Walkerton, de 1088 indivíduos que forneceram dados 8 anos após um trágico surto de veiculação hídrica em Walkerton, Ontário, Canadá, 706 $(64,9 \%)$ apresentavam gastroenterite aguda. Em comparação com indivíduos não expostos, pacientes que tiveram gastroenterite aguda durante o surto relataram sintomas dispépticos significativamente mais prevalentes (Ford et al., 2010).

A dispepsia funcional pós-infecciosa é considerada uma doença de distinta entidade clínica. Uma metanálise da dispepsia funcional pós-infecciosa sugere que a prevalência média de dispepsia funcional após gastroenterite aguda foi de 9,6\% na população adulta. Vários patógenos foram relatados como associados com DF pós-infecciosa, incluindo norovírus, G. lamblia, Salmonella spp., E. Coli O157 e espécies de Campylobacter em Walkerton, no entanto, nenhum desses patógenos propostos teve os postulados de Koch totalmente realizada (Futagami, Itoh \& Sakamoto, 2015).

Spiller et al. (2010), propôs uma hipótese intrigante de que em distúrbios gastrointestinais funcionais pós-infecciosos, a distribuição da infecção aguda (e a inflamação intestinal resultante) pode estar ligada ao resultado dos sintomas. Se a infecção for limitada ao intestino proximal, os pacientes têm maior probabilidade de desenvolver sintomas de DF, mas quando o intestino distal ou cólon está envolvido, os sintomas de SII podem se desenvolver; se ambos o trato intestinal proximal e distal é infectado, uma sobreposição síndrome de SII e DF pode ser mais provável. Mais dados são necessários para confirmar este conceito.

O papel do H. pylori na gênese do DF permanece controverso. A prevalência de infecção por H. pylori em pacientes com DF varia em uma série de estudos, no entanto, não há diferenças consistentes em qualquer a prevalência ou gravidade dos sintomas de dispepsia entre DF positivo para H. pylori e DF negativo para H. pylori. No entanto, está estabelecido que a terapia de erradicação do H. pylori pode melhorar os sintomas em uma minoria de pacientes com DF e pode reduzir o desenvolvimento de úlcera péptica em comparação com aqueles com nenhuma terapia de erradicação (Fock, 2011; Du et al., 2016).

Luzza et al. (1995), ressaltam em sua metanálise que se tornou claro que H. pylori desempenha um papel etiológico na gastrite crônica, doença de úlcera péptica, e possivelmente no câncer gástrico e que a resposta imune da mucosa gástrica pode representar um mecanismo patogenético principal nas doenças associadas ao $\mathrm{H}$. pylori.

Nos estudos selecionados neste artigo, as alterações inflamatórias demonstradas não correspondem às alterações observadas anteriormente na SII. Não houve dados sobre alterações pós-inflamatórias simultaneamente envolvendo o TGI superior e inferior. Realizar estudos em biópsias retiradas do duodeno e reto é necessário para resolver este problema.

As doenças atópicas comumente coexistem com doenças gastrointestinais funcionais desordenadas. Em um dos estudos analisados em nosso artigo, que tem seu objetivo descrito no quadro 1, de 23.000 pacientes com base no Health Banco de dados da Rede de Melhoria no Reino Unido, em pacientes com FGIDs (síndrome do intestino irritável, dispepsia funcional, crônica constipação idiopática), uma elevação consistente na prevalência de doenças atópicas (asma, eczema, rinite alérgica / febre do feno e conjuntivite) foram observadas, especialmente naqueles com múltiplos FGIDs. Além disso, as doenças reumatológicas autoimunes foram, em particular, significativamente mais frequentes em pacientes com DF, constipação e vários FGIDs (Jones, Walker, Ford \& Talley, 2014).

Em um estudo endoscópico em Londres, a eosinofilia duodenal foi observada com mais frequência em pacientes com história de alergia, e a história alérgica foi mais comum em pacientes com Síndrome de Angústia Pós-Prandial em comparação 
com controles. Esta sobreposição sugere que doenças atópicas e autoimunes podem, via ativação da imunidade aprimorada, levar a dispepsia funcional (Walker et al., 2010).

Transtornos psiquiátricos comórbidos, como depressão maior, ansiedade e transtornos somatoformes, são altamente prevalentes em pacientes com FGID. O aumento dos escores de ansiedade antes do surto foi associado a uma redução nas células T CD4 + que expressam interleucina-2 no momento da infecção, células que estão envolvidas na produção de citocinas Th1 e na homeostase imune. Além disso, uma resposta imune mais distorcida em Th2 durante o desafio infeccioso predispôs à progressão para SII-PI. Além da modulação imunológica, o estresse mostrou induzir o exagero da resposta neuroendócrina em SII. Outros relataram uma atividade hipofisária e adrenocortical mais baixa em pacientes com FGIDs (Aro, Talley, Johansson, Agréus \& Ronkainen, 2015).

Ao todo, parece haver uma ligação estreita entre os fatores psicológicos e o risco de desenvolver FGIDs. Os estressores psicológicos contribuem para a iniciação e o curso dos FGIDs, potencialmente por meio de mecanismos que envolvem a modulação imunológica e o processamento cerebral alterado de sinais nociceptivos recebidos. A liberação induzida pelo estresse de mediadores de mastócitos, histamina, triptase e serotonina, desencadeia a sensibilização de neurônios nociceptivos aferentes, levando à percepção aberrante da dor visceral (Wouters \& Boeckxstaens, 2016).

Segundo Jones et al. (2014), há uma prevalência maior de desenvolver algum transtorno de humor, como ansiedade e depressão, em pacientes com FGID do que em pacientes sem FGID, principalmente quando relacionados a DF. O estudo ainda relata que uma atividade imunológica no cólon com alta carga inflamatória está diretamente ligada à depressão, bem como também a liberação de TNF- $\alpha$ por meio dessa desregulação causada está relacionada aos transtornos de humor.

Jones et al. (2019) ressaltam que já na infância os fatores psicológicos exercem certa influência. Pode-se citar o temperamento, condição de saúde mental, preocupação dos pais, vulnerabilidade psicossocial e estresse materno com fatores que aumentam a prevalência na população pediátrica de dor abdominal e esta constitui um fator de risco para que o indivíduo venha a desenvolver algum Distúrbio Gastrointestinal Funcional.

De acordo com a avaliação das evidências feitas pelo sistema GRADE, pode-se concluir que os estudos selecionados apresentam fortes pontos que correlacionam a Dispepsia Funcional com suas repercussões imunes sistêmicas, que abrangem condições neuropsíquicas, infecciosas, alérgicas e inflamatórias. As limitações detêm-se a ínfima quantidade de estudos acerca da temática, o reduzido tamanho amostral de alguns dos estudos e a grande variação de tempo entre as publicações. Mas ainda assim, pela análise estatística, a maioria dos resultados foi significativa, tornando forte a recomendação para uma análise clínica que integre os diversos sistemas afetados pela complexidade desta patologia, permitindo um melhor manejo dos pacientes.

\section{Considerações Finais}

A Dispepsia Funcional mostrou-se intimamente relacionada com o maior risco de desenvolver doenças atópicas e transtornos de humor do que em pacientes que não possuíam a patologia. Os distúrbios imunológicos relacionados a desregulação dos componentes do sistema imune, principalmente os Linfócitos TCD4+ e na expressão do Th1 e Th2, mostraram-se como fatores desencadeantes para surgimento de asma, eczema, rinite, conjuntivite alérgica, depressão e ansiedade. O mecanismo imune normalmente está relacionado a quadros infecciosos, em que a inflamação causada gera alguns mediadores comuns entre tais doenças e, atrelado a fatores genéticos e ambientais, acarreta maior predisposição.

O processo inflamatório mediado por citocinas do Th2 mostrou-se como o principal fator causador dessas outras doenças. As interleucinas presentes em cada fase do desenvolvimento da doença variaram. Na fase aguda, a IL-10 pode encontrar-se aumentada, o que explica uma maior estimulação de produção de citocinas do Th2, enquanto que posteriormente a IL-10 apresentou-se diminuída. Com o aumento na expressão do Th2, há também uma maior proliferação de células B, que se 
diferenciam em plasmócitos secretores de anticorpos. Atrelado a isso, os pacientes com DF apresentaram uma estimulação mitogênica à produção linfocítica de IL-5 e IL-13, que são citocinas presentes em respostas alérgicas e contra helmintos, que podem estar presentes em processos infecciosos.

Com isso, é possível correlacionar o surgimento de outras doenças a partir do distúrbio inicial da DF, tendo em vista que os mecanismos imunológicos da doença acabam tendo repercussões sistêmicas em locais semelhantes de atuação das citocinas geradas pelo desequilíbrio dessa resposta ao estresse causado no organismo. Contudo, faz-se necessário investir em mais artigos que possam elucidar melhor como tais vias podem estar sobrepostas.

\section{Referências}

Aro, P., Talley, N. J., Johansson, S., Agréus, L., \& Ronkainen, J. (2015). Anxiety is linked to new-onset dyspepsia in the Swedish population: a 10-year follow-up study. Gastroenterology, 148(5), 928-937. https://doi.org/10.1053/j.gastro.2015.01.039

Burns, G., Pryor, J., Holtmann, G., Walker, M. M, Talley, N. J, \& Keely, S. (2019). Immune Activation in Functional Gastrointestinal Disorders. Gastroenterology \& hepatology, 15(10), 539-548.

Collins, S. M. (2014). A role for the gut microbiota in IBS. Nature reviews. Gastroenterology \& hepatology, 11(8), 497-505. https://doi.org/10.1038/nrgastro.2014.40

Donato, H., \& Donato, M. (2019). Etapas na Condução de uma Revisão Sistemática. Acta Médica Portuguesa, 32(3), 227-235. https://doi.org/10.20344/amp.11923

Du, L. J., Chen, B. R., Kim, J. J., Kim, S., Shen, J. H., \& Dai, N. (2016). Helicobacter pylori eradication therapy for functional dyspepsia: Systematic review and meta-analysis. World journal of gastroenterology, 22(12), 3486-3495. https://doi.org/10.3748/wjg.v22.i12.3486

Fan, K., Talley, N. J. (2017). Functional dyspepsia and duodenal eosinophilia: A new model. Journal of Digestive Diseases, 18(12), 667-677. https://doi.org/10.1111/1751-2980.12556

Fock, K. M. (2011). Functional dyspepsia, H. pylori and post infectious FD. Journal of gastroenterology and hepatology, 26 Suppl 3, 39-41. https://doi.org/10.1111/j.1440-1746.2011.06649.x

Ford, A. C., Thabane, M., Collins, S. M., Moayyedi, P., Garg, A. X., Clark, W. F., \& Marshall, J. K. (2010). Prevalence of uninvestigated dyspepsia 8 years after a large waterborne outbreak of bacterial dysentery: a cohort study. Gastroenterology, 138(5), 1727-e12. https://doi.org/10.1053/j.gastro.2010.01.043

Futagami, S., Itoh, T., \& Sakamoto, C. (2015). Systematic review with meta-analysis: post-infectious functional dyspepsia. Alimentary pharmacology \& therapeutics, 41(2), 177-188. https://doi.org/10.1111/apt.13006

Galvão, T. F., \& Pereira, M. G. (2015). Avaliação da qualidade da evidência de revisões sistemáticas. Epidemiologia e Serviços de Saúde, 24(1), 173-175. http://dx.doi.org/10.5123/S1679-49742015000100019

Jones, M. P., Walker, M. M., Ford, A. C., \& Talley, N. J. (2014). The overlap of atopy and functional gastrointestinal disorders among 23,471 patients in primary care. Alimentary pharmacology \& therapeutics, 40(4), 382-391. https://doi.org/10.1111/apt.12846

Jones, M. P., Faresjö, Å., Beath, A., Faresjö, T., \& Ludvigsson, J. (2020). Abdominal Pain in Children Develops With Age and Increases With Psychosocial Factors. Clinical gastroenterology and hepatology: the official clinical practice journal of the American Gastroenterological Association, 18(2), 360-367.e1. https://doi.org/10.1016/j.cgh.2019.04.036

Kindt, S., Van Oudenhove, L., Broekaert, D., Kasran, A., Ceuppens, J. L., Bossuyt, X., Fischler, B., \& Tack, J. (2009). Immune dysfunction in patients with functional gastrointestinal disorders. Neurogastroenterology and motility: the official journal of the European Gastrointestinal Motility Society, 21(4), 389398. https://doi.org/10.1111/j.1365-2982.2008.01220.x

Kindt, S., Tertychnyy, A., de Hertogh, G., Geboes, K., \& Tack, J. (2009). Intestinal immune activation in presumed post-infectious functional dyspepsia. Neurogastroenterology and motility: the official journal of the European Gastrointestinal Motility Society, 21(8), 832-e56. https://doi.org/10.1111/j.13652982.2009.01299.x

Koloski, N. A., Jones, M., Weltman, M., Kalantar, J., Bone, C., Gowryshankar, A., Walker, M. M., \& Talley, N. J. (2015). Identification of early environmental risk factors for irritable bowel syndrome and dyspepsia. Neurogastroenterology and motility: the official journal of the European Gastrointestinal Motility Society, 27(9), 1317-1325. https://doi.org/10.1111/nmo.12626

Liebregts, T., Adam, B., Bredack, C., Gururatsakul, M., Pilkington, K. R., Brierley, S. M., Blackshaw, L. A., Gerken, G., Talley, N. J., \& Holtmann, G. (2011). Small bowel homing $\mathrm{T}$ cells are associated with symptoms and delayed gastric emptying in functional dyspepsia. The American journal of gastroenterology, 106(6), 1089-1098. https://doi.org/10.1038/ajg.2010.512

Luzza, F., Imeneo, M., Maletta, M., Monteleone, G., Doldo, P., Biancone, L., \& Pallone, F. (1995). Isotypic analysis of specific antibody response in serum, saliva, gastric and rectal homogenates of Helicobacter pylori-infected patients. FEMS immunology and medical microbiology, 10(3-4), 285-288. https://doi.org/10.1111/j.1574-695X.1995.tb00045.x

Sousa, M. N. A., \& Santos, E. V. L. (2016). Medicina e pesquisa: um elo possível. Editora Prisma. 
Research, Society and Development, v. 10, n. 9, e17810917785, 2021

(CC BY 4.0) | ISSN 2525-3409 | DOI: http://dx.doi.org/10.33448/rsd-v10i9.17785

Spiller, R. (2010). Postinfectious functional dyspepsia and postinfectious irritable bowel syndrome: different symptoms but similar risk factors. Gastroenterology, 138(5), 1660-1663. https://doi.org/10.1053/j.gastro.2010.03.024

Talley, N. J., Holtmann, G., \& Walker, M. M. (2015). Therapeutic strategies for functional dyspepsia and irritable bowel syndrome based on pathophysiology. Journal of gastroenterology, 50(6), 601-613. https://doi.org/10.1007/s00535-015-1076-x

Walker, M. M., Salehian, S. S., Murray, C. E., Rajendran, A., Hoare, J. M., Negus, R., Powell, N., \& Talley, N. J. (2010). Implications of eosinophilia in the normal duodenal biopsy - an association with allergy and functional dyspepsia. Alimentary pharmacology \& therapeutics, 31(11), 1229-1236. https://doi.org/10.1111/j.1365-2036.2010.04282.x

Wouters, M. M., \& Boeckxstaens, G. E. (2016). Is there a causal link between psychological disorders and functional gastrointestinal disorders? Expert review of gastroenterology \& hepatology, 10(1), 5-8. https://doi.org/10.1586/17474124.2016.1109446

Wu, H., \& Wu, E. (2012) The role of gut microbiota in immune homeostasis and autoimmunity, Gut Microbes, 3(1), 4-14, https://doi.org/10.4161/gmic.19320 